\title{
Case study of energy efficiency and electric power quality
}

\author{
C. Oliveira ${ }^{1}$, F. Sato ${ }^{1}$, E. Ruppert and M. Kubo ${ }^{1}$ \\ ${ }^{1}$ School of Electrical and Computer Engineering \\ Unicamp - University of Campinas \\ Av. Albert Einstein, 400 Campinas (Brazil) \\ Phone number: +55 193521 3720, e-mail: caio@dsee.fee.unicamp.br, sato@dsee.fee.unicamp.br, \\ ruppert@fee.unicamp.br, massakit@dsce.fee.unicamp.br
}

\begin{abstract}
This paper describes the results of the electrical energy efficiency and power quality evaluation done in the School of Electrical and Computer Engineering of the University of Campinas (Unicamp) in São Paulo State, Brazil, through the Project named Ecogera. The analysis was based on the electrical signals acquired in the switchgear of the Students Classroom Building of the School of Electrical and Computer Engineering using measurement and energy management instruments. The replacement of the old lightning system using $40 \mathrm{~W}$ old fashion fluorescent bulbs mounted on non reflective fixtures by new energy save $32 \mathrm{~W}$ fluorescent bulbs mounted on reflective fixtures reduced expressively the electrical energy consumption and the installation electrical power demand. The measurements allowed to know the details of harmonic distortions and disturbances that affect voltage magnitude and current.
\end{abstract}

\section{Key words}

Energy Efficiency, Measurements, Power Quality.

\section{Introduction}

In 2001, due to the energy crisis, the Brazilian federal government created the Board of Management of Electricity Crisis, which aimed to manage the supply of electricity rationing by $20 \%$ of electrical energy between June 2001 and February 2002, especially in the Southeast, Midwest and Northeast. After the crisis it was demonstrated the need for rational use of electricity by various segments of society. Thus, at University of Campinas (Unicamp) it was implemented a pilot project to assess the energy efficiency through a program of rational use of energy and exploration of alternative sources of electricity.

Unicamp is considered one of the major consumers of the Metropolitan Region of Campinas, with monthly consumption ranging between 4,700 and 6,100 MWh and demand around $18 \mathrm{MW}$. The electrical energy is supplied by the $11.95 \mathrm{kV}$ substation of $138 / 11.95 \mathrm{kV}$ of Companhia Paulista de Forca e Luz (CPFL) with a power transformer of 25 MVA and exclusive distribution of electricity is carried out through five feeders.

\section{Ecogera Project}

Ecogera Project, funded by FINEP (Studies and Projects Financing agency) and managed by FEEC (School of Electrical and Computer Engineering of Unicamp) and NIPE (Interdisciplinary Center of Energy Planning of Unicamp), comprises two modules: energy conservation and electricity generation through alternative energy sources (in this case, specifically, natural gas).

This paper describes only the first module, which aims to achieve the energy efficiency assessment in Unicamp using an initial generation working cell, consisting of four characteristic units of energy consumption in the university in relation to the type of activity performed in each one focused on reducing energy consumption in lighting.

\section{A. Consumption units}

The initial working cell is composed by four different units of work of the university: an administrative building, another of classrooms, one for research and teaching and one hospital. In general, each unit is fed by more than one transformer. Because there were no meters in sufficient quantity to be installed in all existing distribution panels in all the units, it was chosen significant switchboards from the point of view of energy consumption of the loads connected to them. The units of consumption analyzed were: DGA (General Directorate of Administration) is the unit purely administrative, $\mathrm{PB}$ (Basic Cycle II) is only one building with classrooms; FEEC (School of Electrical and Computer Engineering) is the institution of teaching, research and extension, and the hospital is the CAISM (Center for Integral Attention to Women's Health). Two meters are installed in the 
hospital and in the Electrical Engineering School and only one in the others.

\section{B. Preliminary studies}

Prior to the acquisition of the new light fixtures, a brief study was developed for the block of classrooms of the FEEC using the criteria established by the Brazilian lightning standard ABNT NBR 5413 (Interior Illuminance), that are similar to the European Standards.

Based on this study and the need for energy savings it was decided to replace the old light fixtures of two electromagnetic ballasts of $40 \mathrm{~W}$ lamps by the light fixtures with two lamps of $32 \mathrm{~W}$ with electronic ballast. The results of the laboratory tests of the new light fixtures are shown in Table I. The substitution of 4 lamps of $40 \mathrm{~W}$ by 2 lamps of $32 \mathrm{w}$ was done following a design done during the first part of the project.

Table I. Reactor Testing

\begin{tabular}{c|c}
\hline $\begin{array}{c}\text { Electromagnetic Reactor } \\
\text { (4 lamps of } \mathbf{4 0} \mathbf{~ W})\end{array}$ & $\begin{array}{c}\text { Electronic Reactor } \\
\text { (2 lamps of 32 W) }\end{array}$ \\
\hline U: $220,03 \mathrm{~V}$ & $\mathrm{U}: 220,93 \mathrm{~V}$ \\
I: $0,9842 \mathrm{~A}$ & $\mathrm{I}: 0,2862 \mathrm{~A}$ \\
P: $162,13 \mathrm{~W}$ & P: $60,30 \mathrm{~W}$ \\
PF: 0,7486 & PF: 0,9535 \\
\hline $\mathrm{U}_{\text {fund }}: 219,98 \mathrm{~V}$ & $\mathrm{U}_{\text {fund }}: 220,83 \mathrm{~V}$ \\
$\mathrm{I}_{\text {fund }}: 0,9736 \mathrm{~A}$ & $\mathrm{I}_{\text {fund }}: 0,2747 \mathrm{~A}$ \\
THDu: $2,20 \%$ & THDu: $3,00 \%$ \\
THDi: $14,81 \%$ & THDi: $14,27 \%$ \\
\hline
\end{tabular}

\section{Predict impacts}

From the results, comparing the two types of light fixtures and lamps, it was estimated a reduction of electric power consumption in the order of $30 \%$ with the replacement and installation of presence sensors in classrooms, as well as the improvement of the power factor of the electrical installation. Measurements were done of brightness intensity in several important points of the classrooms verifying that the level of the local illuminance, with the use of new light fixtures, were in accordance with the tables presented in several lightning standards. The presence sensors reduced the consumption of electricity because they prevent the lights to remain on in environments where there are no people.

\section{Description of used meters}

For the data acquisition six meters of Power Measurement Company type ION 7600 were used. These meters have true RMS measurement of voltage and current and also power and energy and the ability to record events and measurements for monitoring the quality of electrical power [1]. These meters are managed by ION Enterprise software, which processes, analyzes, stores and shares information collected from network. It consists of two main programs: ION Vista and ION Reporter.
The ION Vista is a software to view, analyse and control, which provides a graphical view of the system, allowing visualization of data snapshots of energy meters or historical data from the database. Recording of quantities like voltage, current, power, power factor, frequency and power quality indexes, and also events like sag, swell and other transient events are possible.

The second allows the definition and creation of reports based on information from the database gotten from the monitoring network. There are some pre-configured reports as Power Quality, Load Profile and Energy and Demand, which can be issued on request of the user, but also it is possible to generate customized reports with data stored.

\section{Measurements and results}

This paper presents measurements and results obtained only in the FEEC locations, since it is the only consumer unit, so far, in which all the measurements before and after changing the light fixtures lamps were made. In other units the installations aren't still in finished.

\section{A. Energy conservation}

The annual load profiles before and after the replacement of the light fixtures and lamps and the installation of presence sensors are shown in Figures 1 to 3. In 2006, due to operational problems the meter was inactive. The change of light fixtures and lamps occurred between April and May 2005, which can be verified in Figure 2. It can be seen, comparing the years 2004 and 2007, that there was a drop in energy demand from $26.4 \mathrm{~kW}$ to 18.1 $\mathrm{kW}$, reaching $31.8 \%$ reduction. One can also see the improvement of power factor, given by the drop of reactive power involved.

Tables II and III show the comparisons of energy demand of 4 months of intense activities in FEEC. Based on the measurements and using the energy value of the local utility it can estimate that the FEEC, only in the blocks of classrooms, would have an annual power spending of around 11,000 USD before the changes against 7,500 USD after changing the light fixtures and lamps, meaning a cost reduction of about $32 \%$.

Table II. Total Energy (kWh)

\begin{tabular}{c|c|c|c}
\hline & $\mathbf{2 0 0 4}$ & $\mathbf{2 0 0 7}$ & Reduction (\%) \\
\hline May & 7388.08 & 4825.73 & 34.70 \\
June & 6868.99 & 4228.18 & 38.40 \\
September & 7164.60 & 4225.04 & 41.00 \\
October & 6648.04 & 4738.70 & 28.70 \\
\hline
\end{tabular}

Table III. Maximum Demand (kW)

\begin{tabular}{c|c|c|c}
\hline & $\mathbf{2 0 0 4}$ & $\mathbf{2 0 0 7}$ & Reduction (\%) \\
\hline May & 25.79 & 17.31 & 32.90 \\
June & 25.17 & 16.27 & 35.40 \\
September & 25.38 & 17.09 & 32.70 \\
October & 26.38 & 17.77 & 32.60 \\
\hline
\end{tabular}



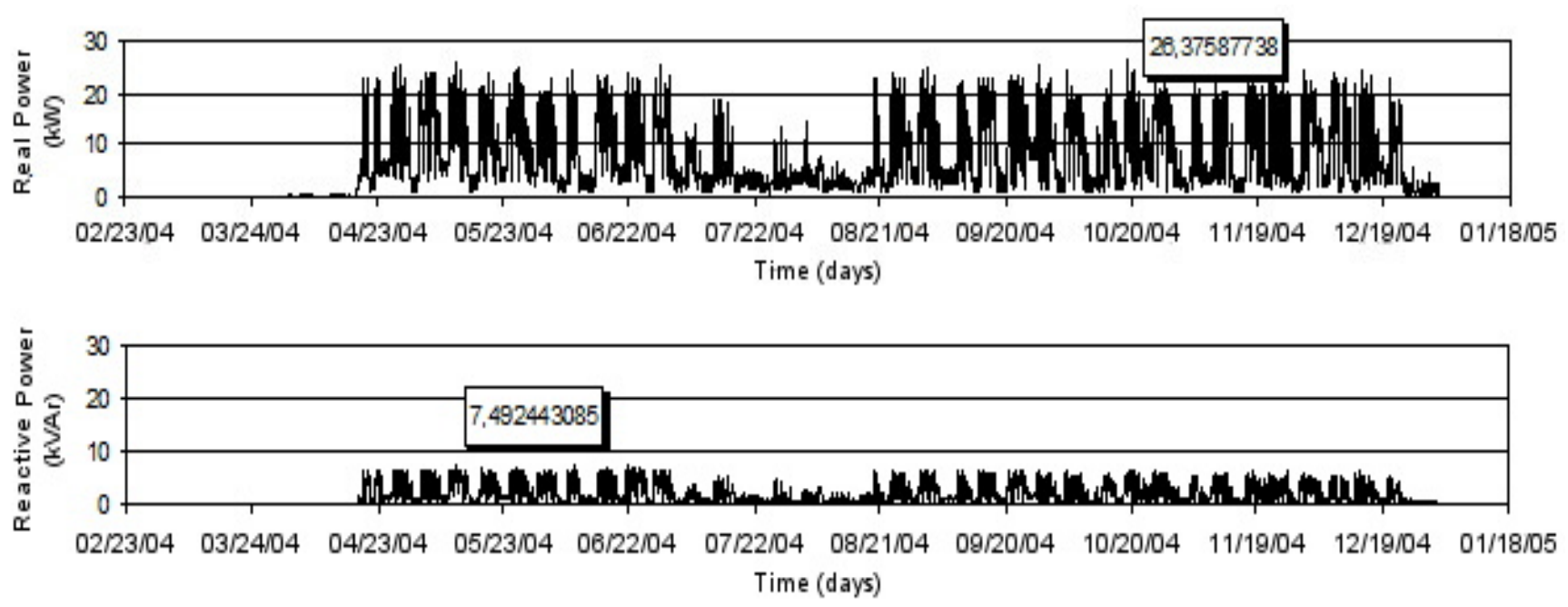

Fig. 1 Load profile in 2004.

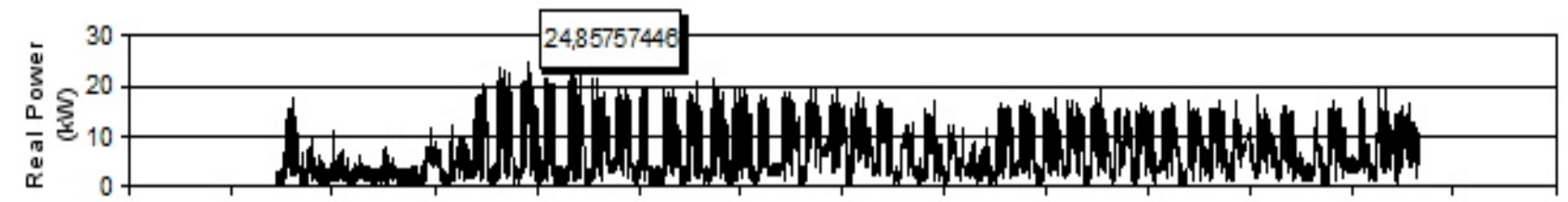

11/19/0412/19/0401/18/0502/17/05 03/19/0504/18/0505/18/0506/17/0507/17/0508/16/05 09/15/05 10/15/0511/14/05 12/14/0501/13/06 Time (days)

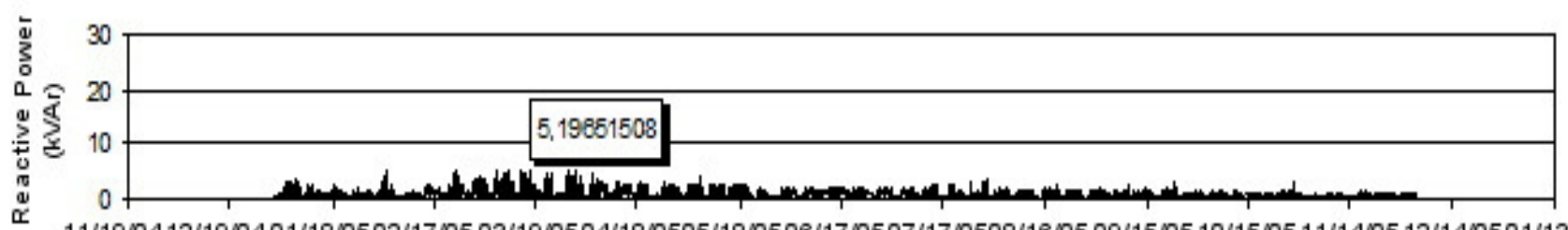

11/19/0412/19/0401/18/0502/17/05 03/19/0504/18/0505/18/0506/17/0507/17/0508/16/05 09/15/05 10/15/0511/14/05 12/14/0501/13/06 Time (days)

Fig. 2. Load profile in 2005.

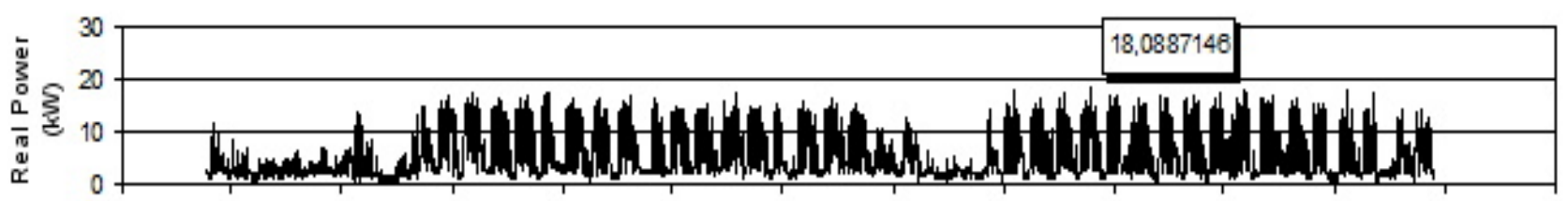

12/09/06 01/08/07 02/07/07 03/09/07 04/08/07 05/08/07 06/07/07 07/07/07 08/06/07 09/05/07 10/05/07 11/04/07 12/04/07 01/03/08 Time (days)

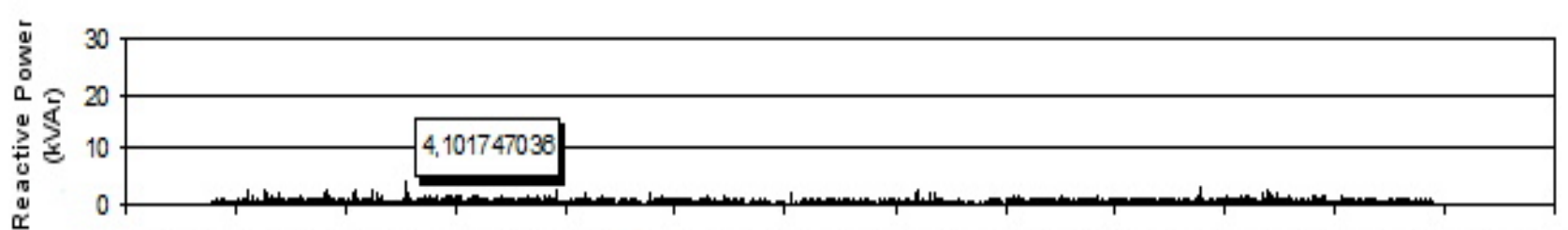

12/09/06 01/08/07 02/07/07 03/09/07 04/08/07 05/08/07 06/07/07 07/07/07 08/06/07 09/05/07 10/05/07 11/04/07 12/04/07 01/03/08 Time (days)

Fig. 3. Load profile in 2007. 


\section{B. Power Quality}

The power quality is related to the changes that may occur in the electrical system. According to [2], the definition of problems related to the power quality is: "any power problem manifested in voltage, current or frequency variations that results in the failure or improper operation consumers electrical equipments."

These problems are growing over the years mainly due to the following reasons: a) increasing in the number of nonlinear loads, which increase the level of harmonics in the network, b) increasing in the sensitivity of the electrical equipment, like medical equipment, c) increasing in the number of equipments based on microprocessors and power electronics components, d) increasing of the electrical grid interconnection, in which the failure of a component generates large and more serious consequences for large part of the electrical system.

There is therefore an increasing interest in the study of phenomena related to power quality due to the fact that problems generated may cause economic impacts for both electric utilities and end consumers [2], [3]. This way, the focus of this part of the paper is the analysis related to the disturbances in the harmonic voltage amplitude caused by the new lightning system used.

\section{1) Analysis of the harmonics}

a. The harmonic spectrum

Due to the fact that fluorescent lamps with electronic ballast be less expensive than other type of lamps, they became popular recently, however they have great disadvantage due to the fact of produce current harmonics in excess [4]. Figures 4 and 5 show, respectively, waveforms of phase currents and its harmonic spectrum observed at the measurement point in FEEC on 02/27/2008 at 10:40 h. The presence of fluorescent lamps with electronic ballasts is evident in the waveforms of the currents and in the predominance of odd harmonics.

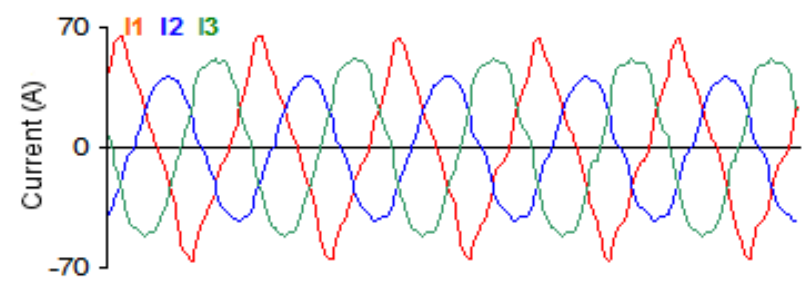

Fig. 4. Current wave for on $02 / 27 / 2008$ at 10:40

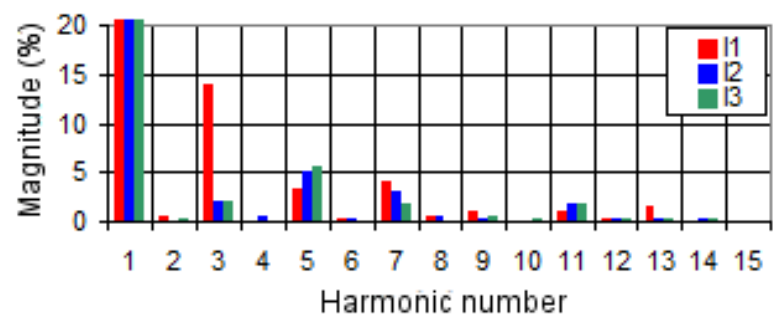

Fig. 5. Current harmonic spectrum on 02/27/2008 at 10:40
It is important to remember that the distortion in the load current is due to the load, while the voltage distortion is due to the current distortion [5]. In Figures 6 and 7 it can be seen the waveforms of three-phase voltages and its harmonic spectrum.

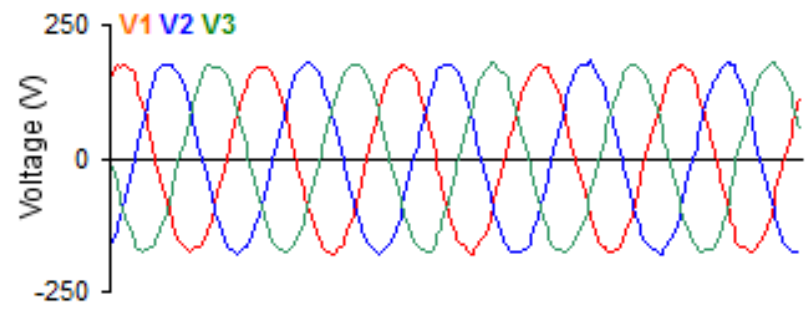

Fig. 6. Voltage wave form on $02 / 27 / 2008$ at 10:40

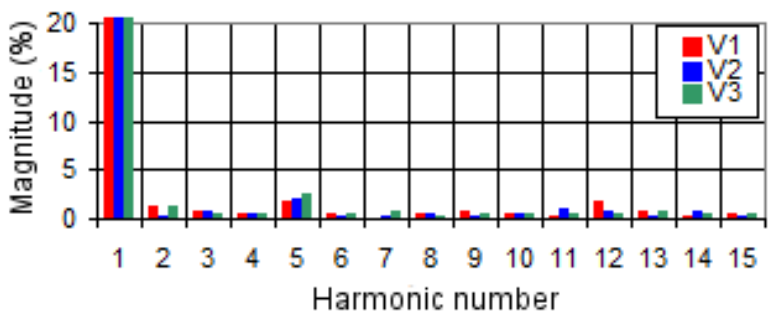

Fig. 7. Voltage harmonic spectrum on $02 / 27 / 2008$ at $10: 40$

b. Rate of total harmonic distortion

The rate of Total Harmonic Distortion (THD) is a widely used performance index to measure the harmonic content of a distorted signal. For a signal Y, the THD is set at (1):

$$
T H D_{Y}=\frac{\sqrt{\sum_{n=2}^{\infty} Y_{n}^{2}}}{Y_{1}}
$$

Where: $\mathrm{THD}_{\mathrm{Y}}$ is the total harmonic distortion of the signal $Y, Y_{n}$ is the magnitude of the $n^{\text {th }}$ harmonic of the signal $\mathrm{Y}$ and $\mathrm{Y}_{1}$ is the magnitude of the fundamental component of $\mathrm{Y}$.

This definition is in accordance with IEC 61000-2-2, which also specifies that $\mathrm{n}$ (harmonic order) may be limited to 50. The THD allows us to evaluate, through a single number, the distortion that affects the current or voltage at a given point in the network.

Figure 8 shows the voltage harmonic distortion during the days of a week on August 2007. It can be seen in the three phases that its value is adequate because they stay under $55 \%$.

In the case of the currents (Figure 9) it is observed a substantial level of harmonic pollution in phase 1 which reaches more than 50\%, and a significant harmonic pollution in phases 2 and 3 as they are kept between 10 and $50 \%[6]$. 


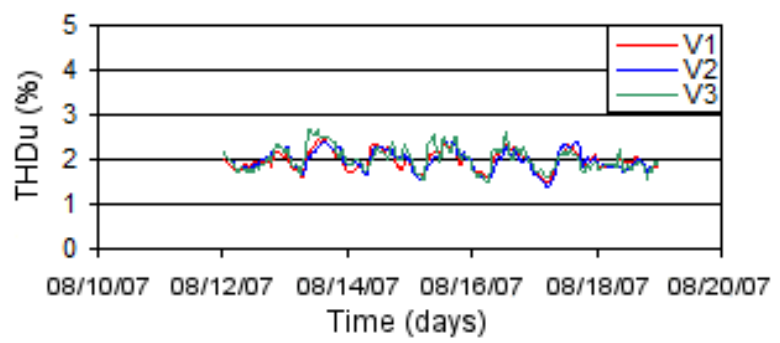

Fig. 8. THD of the voltage during one week in August 2007.

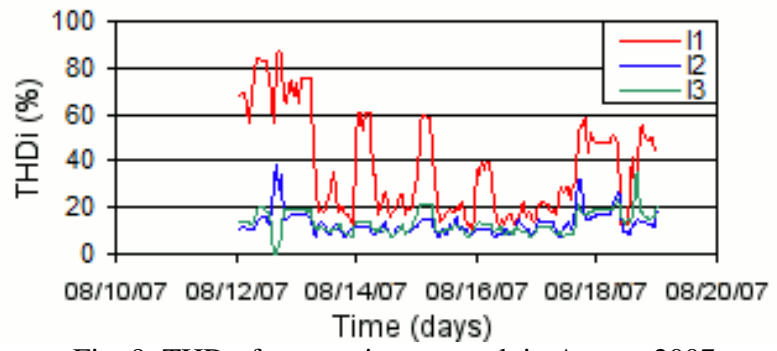

Fig. 9. THD of current in one week in August 2007.

2) Analysis of the disturbances in the amplitude of the voltage

ITI Curve (CBEMA) describes the envelope of the AC input voltage for most of the information technology equipment without loss of its job function and can be used for both steady state and for transient conditions. This curve is applied to the rated voltage of $120 \mathrm{~V}$ and frequency of $60 \mathrm{~Hz}$ [7].

Figure 10 shows this curve, which can be used to assess the quality of the voltage in an electrical power system referring to sags and swells voltage, interruptions and transients. In the abscissa there is the duration of the event and its magnitude appears in the ordinate. In the region between the curves No Interruption Function it is expected that the equipment operates in regular way. Below the envelope, No Damage Region, operation fail or malfunction may occur. Above the envelope, Prohibited Region, the equipment may be damaged [8].

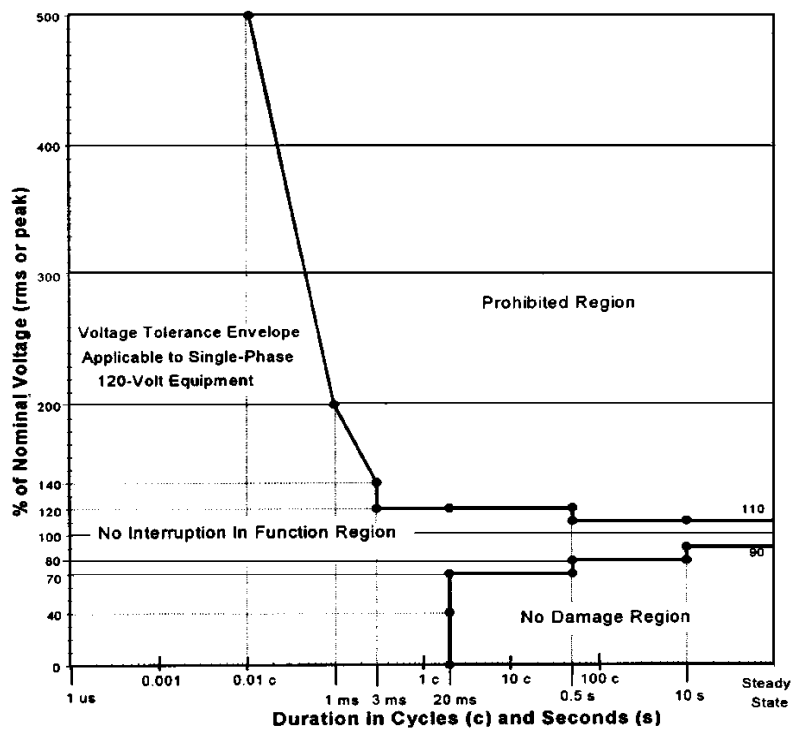

Fig. 10. Curve ITI (CBEMA).
All recorded incidents in the period of 3 years in the FEEC electrical installation were put on the curve ITI (CBEMA), as illustrated in Figure 11, confirming that the following incident exceeded tolerance: 10 sags, 3 swells, 3 interruptions and 52 transients.

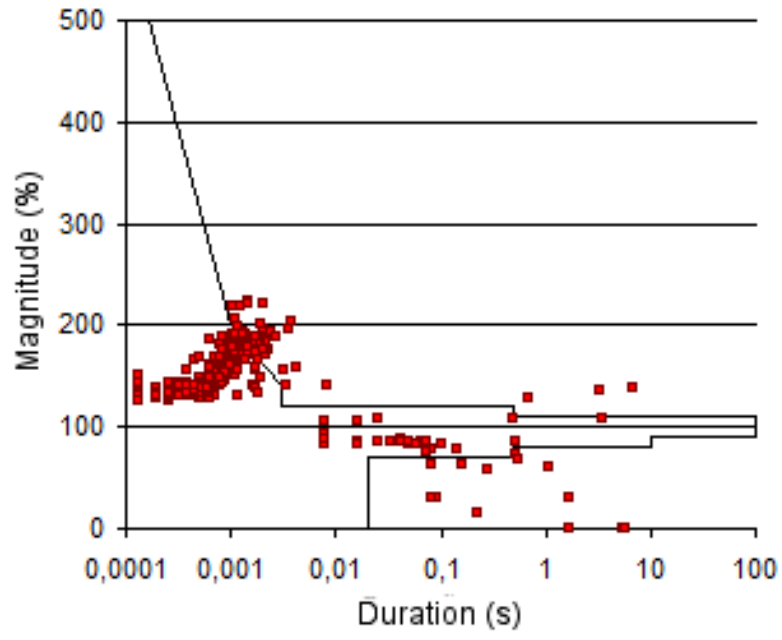

Fig. 11. Curve ITI (CBEMA) for disturbances occurred between 2004 and 2007.

\section{Conclusion}

Throughout this work it could be seen that the lighting system using $32 \mathrm{~W}$ fluorescent lamps with electronic ballast and reflective lamps fixture was very effective regarding energy conservation, however the distortion it causes in the currents can become worrisome. For large consumers it became almost indispensable to equip themselves with a measurement system to monitor the electrical installation. The records of types of occurrences are extremely important for the identification of possible problems caused in electrical equipment and for taking efficient corrective and predictive efficient actions.

It is noted that the number of occurrences of swell that exceed the tolerance are well below to those of sags, corroborating the literature descriptions.

This pilot project will serve as a basis for the establishment of a general system for measuring and monitoring on the University Campus. This providence is already partially under Master Plan Unicamp with the implant of 10 Measurement Centers and 1 Operation and Monitoring Center.

\section{Acknowledgments}

The authors thank FINEP and CNPq for financial support. 


\section{References}

[1] ION 7600: User's Guide, Power Measurement, Canada (2003).

[2] R. Dugan, M. McGranaghan, S. Santoso and H. Beaty, Electrical Power Quality Systems, McGraw-Hill, 2nd ed., New York (2002).

[3] J. Afonso and J. Martins, "Qualidade de Energia Elétrica", Revista o Eletricista (2004), Year 3, n. 9, pp. 66-71.

[4] D. Chapman, Power Quality Application Guide - Harmonics: Causes and Effects, Copper Development Association, United Kingdom (2001).

[5] H. Moreno, Harmônicas nas Instalações Elétricas: Causas, Efeitos e Soluções, Procobre - International Copper Association Brazil, São Paulo (2001).

[6] S. Volut and J. Schonek, Electrical Installation Guide According to IEC International Standards, Schneider Electric, France (2007).

[7] Information Technology Industry Council (ITI), ITI (CBEMA) Curve Application Note, Washington (2000). Available at: <http://www.itic.org/archives/iticurv.pdf>. Accessed on: September 11, 2007.

[8] J. Arrillaga, M. Bollen and N. Watson, " Power Quality Following Deregulation", Proceedings of the IEEE (2000), Vol. 88 , n. 2, pp. 246-261. 